\title{
Sampling Theoretically for Comparison
}

\author{
Adeyemi Adebayo and Barry Ackers \\ College of Accounting Sciences, University of South Africa, Africa \\ ackerb@unisa.ac.za
}

\begin{abstract}
Sampling has historically been one of the major challenges of the comparative research approach. These sampling challenges primarily result from the way researchers select the cases/samples for the study. In this regard, researchers have to a large extent tended to employ non-probability convenience and purposive sampling techniques. Even though it may be argued that these sampling approaches need not be theory driven as samples tend to evolve in the process of research, more often than not, these sampling methods, especially in comparative research designs, while skewing research attention towards over-researched countries and cases, wealthy nations and incomparable cases, also introduce an element of bias into sampling and therefore into research findings. Thus, this paper argues for a move away from the simplicity of purposive and convenience sampling, to one of the more robust forms of theoretical sampling, in order to improve the research rigour associated with the comparative methodological approach. This paper accordingly postulates this may be achieved by engaging in some form of theoretical sampling. In this regard, this paper describes a two-phase method for generating comparative samples from theories, involving six distinct steps.
\end{abstract}

Keywords: Comparative analysis; organisational analysis; public sector accounting; qualitative comparative analysis (QCA); theoretical arguments; theoretical sampling; theory verification and generation

\section{Introduction}

Traditionally, in carrying out comparative studies in fields such as sociology, accounting, political science, public management and public administration, researchers have generated comparative samples or cases, using some form of convenience or purposive sampling, especially when selecting stage one samples, which is usually not possible in probability sampling. Stage one sampling entails macro sample selection of country or society, while stage two sampling entails micro selection of samples within the stage one sample, country or society. Yin (2014) discussed this stage two sampling in the frame of embedded unit, which entails conducting case studies within countries. One of the constraints in convenience sampling is that when making selection decisions as well as in selecting cases, researchers themselves knowingly or unknowingly conclude that their perspective is correct and therefore superior to others (Allardt, 1990), or that cases are comparable when they may not be (Aldrich, 2009). As such, researchers often may have some vested interest in such sampling, which could affect data emerging from such processes, especially in qualitative comparative studies (Martinus and Hedgcock, 2015). Although the researchers' assumptions may be correct in some situations, these assumptions tend to introduce bias into sampling.

Despite most researchers endeavouring to ensure that their research processes are rigorous, concerns about reliability and validity (both internal and external) remains. This is because all empirical observation must in some way be related to theoretical constructions, as theoretical construction does not have any value when it is not in some way related to empirical observations (Oyen, 1990; Johns, 2001). Thus, irrespective of whether researchers strive to demonstrate that the research process is rigorous, or not, results will be questioned when observers note the absence of a connection between the sample and data, and equally among sample, data and theory. In this respect, generating samples from theories is an important activity in research, especially in comparative social science research. In addition to improving the confidence of observers in the research process and the research findings, this reduces researcher bias and ensures that both descriptive (inductive) and prescriptive (deductive) comparative analyses are possible (Burnham et al., 2008; Thomas, 2008). Although some researchers may argue that theories do not have to be prespecified in sampling, since theory may evolve during the fieldwork, as argued by Miles and Huberman (1994), this may not be problematic in purely qualitative research designs, but could nevertheless introduce concerns in comparative research designs.

Validity is concerned with how a quantitative researcher persuades his/her audience that the findings of an enquiry are worth paying attention to, and taking account of (Lincoln and Guba, 1985). Reliability on the other hand entails demonstrating that a study's operations, including but not limited to data collection procedures, can be repeated, with the same results (Yin, 2014). Since this study discusses the comparative approach, which is applicable in both quantitative and qualitative approaches, the terms validity and reliability have been used for both the quantitative and qualitative research components (Morse, et al, 2002). 
Along these lines, this paper describes how comparative samples may be generated from theories. Although several features of this process have been discussed in prior literature, tensions nevertheless abound about how to generate samples in terms of the starting point, whether comparative samples should be selected for theory generation, or verification and how to proceed with building samples for theory verification, as well as for generation and verification as distinct from the process of building samples for theory generation. In addition, there appears to be a lack of clarity relating to the procedures for generating comparative samples, within the context of the role played by the type of comparative study to be conducted and the literature. Collectively, these reasons imply that despite the importance of generating samples from theories, it has not yet been clearly articulated by researchers.

This article therefore attempts to make three contributions to the comparative literature. The first and the main contribution is to describe the process for generating comparative cases from theoretical arguments. The second shows that even though the comparative approach may be used in generating theories, as is the case with most versions of comparative sampling (Whetten, 2009; Huarng and Roig-Tierno, 2016), it remains more of a theory verification/underpinning process. The third situates this sampling approach within other sampling techniques, as well as within the larger social science research context.

Having provided the rationale for this study, this paper proceeds by presenting the background to the study. Thereafter, an overview of the comparative approach is presented, before the problems associated with the comparative approach are discussed, which leads to the development a six-stage process for building comparative samples from theories. Following this, this paper discusses how to evaluate usable theories, before comparing the sampling procedure discussed in this paper with other case selection and comparative approaches. The paper concludes thereafter and provides avenues for future research.

\section{Background}

Many authors have knowingly and unknowingly attempted to demonstrate that research sampling is possible without using the traditional probability and non-probability sampling techniques (Glaser and Strauss, 1967; Kohn, 1989a; Kohn, 1989b; Peters, 1994; Druckman, 2005; Berg-Schloser and De Meur, 2009; Berg-Schlosser et al., 2009). The earliest work in this context is that of Glaser and Straus (1967), who showed that cases could be selected and data gathered based on theories (Glaser and Strauss, 1967; Eisenhardt, 1989). In a more recent article, Druckman (2005), writing on case studies, notes that it is possible for theories or concepts to guide case selection and description in a focused case comparison, which is one of the four categories of the case studies he developed (see also Peters, (1994) for theoretical case study; Eisenhardt, (1989) for a discussion on Glaser and Strauss (1967) theoretical sampling; and Berg-Schloser and De Meur (2009) on case and variable selection). In addition, Yin (2014) provided helpful advice on how to select cases for replication, either literally or theoretically (the latter being aimed at predicting contrasting results, but for anticipatable reasons. However, it appears that authors have not clearly elaborated the process of sampling theoretically for comparative studies. These arguments have subsequently been misinterpreted and incorrectly applied by several authors, especially the arguments of Glaser and Strauss (1967), resulting in evidence of disjointed theoretical sampling processes emerging in the literature. Regardless of this, significant tension remains concerning how to proceed by combining these disjointed elements to form a whole when contemplating undertaking any form of comparative study and generating cases for analysis generally.

\section{The Comparative Approach}

The comparative research approach refers to an interdisciplinary research approach (Harrison and Callan, 2013) that focuses on comparing elements that are both similar on the one hand, but different on the other. It accordingly follows that the comparative approach is used in the natural sciences, sociology, accounting, political science, economics, medicine, law and so on (Tuene, 1990; Whetten, 2009), albeit in different forms and on different issues. The comparative approach may be used to analyse organisations, organisational actors, organisational activities, organisational practices, countries, behaviour, events, objects and chemical reactions under experimental condition etc. These are known as cases or samples in comparative studies. Thus, comparative analysis represents a form of case study as indicated above. However, while the case study approach usually focuses on a single case, the comparative study focuses on a number of cases. As such, the comparative approach is a pragmatic response to the limitations of the single-case (case study) approach (Schutt, 2012). In this regard, it is important to note that most organisational analyses are sociological with an aspect of organisational economics component (see Williamson (1981) on the Economics of Organisation), 
tending towards political analyses of nations and organisations in nations. In this regard, comparative analyses in political science and public administration/management are usually on individuals, organisations and, more recently, largely on nations (Wilson, 2011), as a way of responding to the new global reality (Jreisat, 2012). Along these lines, King, Felin and Whetten (2009) note two variants of sociological comparative analyses: organisational forms and cross-cultural analyses. While organisational forms entail comparing organisation forms such as markets, hierarchies and hybrids, the cross-cultural analysis entails comparing countries.

This comparative approach can be used in accomplishing different ends: generating theory, underpinning theory, extending theory and testing theory (Kohn, 1989a; 1989b). More recently, this comparative approach has assumed the important role of comparison between symmetric (e.g. MRA and SEM) versus asymmetric qualitative comparative analysis (QCA) (e.g. analysis by quintiles and by fuzzy set QCA) (Huarng and Roig-Tierno, 2016; Fainshmidt et al., 2020; Gligor et al., 2020). Authors do not however, agree on the research issue for which the comparative approach should be applied. While some authors have argued that the comparative approach should be used strictly for theory verification (Warwick and Osherson, 1973; Oyen, 1990; Tuene, 1990; Aldrich, 2009), some believe that it is both a theory verification and generation approach (Glaser and Strauss, 1967; Peters, 1994; Burnham et al., 2008; Thomas, 2008) with others believing that it is strictly a theory generating approach (Berg-Schlosser et al., 2009; Toshkov, 2016). In this regard, Peters (1994) contends that the idea that comparative research is the principal tool for generating theory in the social sciences is merely a matter of emphasis, whereas Glaser and Strauss (1967) argue that the comparative approach works better with theory generation. Within this context, Glaser and Strauss (1967) have provided an excellent clarification and assessment on comparison for verification, comparison for assumed verification and limited generation and comparison for generation. It is self-evident that despite the comparative approach being more applicable as a theory verification tool, it may equally be used for generating theories, as well as for both generating and verifying theories together.

\subsection{Issues with the comparative approach}

Since the comparative approach is mostly used in cross-country analysis, many documented challenges relating to comparative analysis have in some way been connected with cross-country analysis. In this way, issues of conceptual equivalence, measurement equivalence and linguistic equivalence appear to be some of the major challenges of the comparative approach (Warwick and Osherson, 1973; Allardt, 1990). Arguably, the most salient problem of the comparative approach relates to sampling, primarily because cases derived from the sampling constitute the main focus of the comparative analysis (Berg-Schlosser et al., 2009; Yamasaki and Rihoux, 2009; Harrison and Callan, 2013). As a result of space limitations, as well as the fact that that most comparative researchers appear to be aware of these issues, they are often well taken care of in comparative studies. However, issues of conceptual equivalence, measurement equivalence and linguistic equivalence are not discussed here. For an overview of conceptual equivalence, see Warwick and Osherson (1973), Allardt (1990) and Harrison and Callan (2013). For an overview of measurement equivalence, see Mahoney (2004). For an overview of linguistic equivalence, see Allardt (1990), Damrosch (2003) and Martinus and Hedgcock (2015).

\subsubsection{Sampling Issue}

Sampling entails choosing a fraction of a group and/or cases to represent the total population, to allow for making some form of generalisation about such a group. Following this description of sampling, it makes sense to conclude that sampling is important for researchers, companies, society and/or organisations. Thus, for the reasons provided below, it is important to study sampling. Within this context, sampling to a large extent determines the validity of studies (Thomann and Maggetti, 2020). Moreover, sampling, when properly conducted has the potential of delivering good research and good research results, and vice versa (Woodside, 2016). In addition, sampling is useful in limiting research bias, which is a vital factor, especially in business and organisation research. Furthermore, sampling ensures that theoretically relevant groups and/or cases are selected (Greckhamer et al., 2018: 7).

In other social science methodologies, such as experimental and survey approaches, the process of sampling usually denotes selecting individuals and organisations as samples. Notwithstanding, as with individuals and organisations, the comparative approach has introduced other forms of sampling, such as selecting countries, departments and organisational units. In this context, Warwick and Osherson (1973) submit that sampling occurs in different ways, which include selecting research sites, the population elements, the choice of indicators used in measuring concepts and in combining indicators into indices. To reiterate the importance of sampling in the comparative approach, Scheuch (1990) contends that the major issue with comparative studies is theoretical, 
one of theory and design, and not technical. It follows that failure to clarify the reasons why a researcher employs a comparative approach, and selects particular settings or cases over others, results in the loss of research artefacts. In the same spirit, Jreisat (2012), submits that purpose and methods are major issues in comparative studies and resolving them always pose a major challenge.

Furthermore, based on Aldrich's (2009) explanations, the three critical problems of the comparative approach noted by Aldrich (2009), i.e. classifiability, generalisability, and predictability, are largely problems related to sampling. In this connection, Burnham et al. (2008), while arguing that the quality of a comparative analysis rests on the cases studied, contends that comparative analysis in which cases are not carefully selected and analysed are not, in a strict sense, adopting the comparative approach. In the comparative approach, selecting countries and societies, which is the first stage of sampling and the sampling of population components within these societies and/or countries, which is the second stage of sampling, are crucial. These steps, to a large extent, not only determine the outcome of comparative analysis, but also ensure the reliability and validity of comparative analysis. When selecting countries or societies, more often than not, researchers do not select samples/cases using probability sampling techniques. Judging by some of the empirical comparative studies that have been conducted to date (see for example, Barzelay and Gallego, 2010; Wada, Kajüter and Moeschler, 2012; Guta, 2013; Ying and Patel, 2016), sample selection appears to follow some form of convenience sampling for stage one sampling, and purposive/convenience for stage two sampling. In some cases, the sampling technique used is not even mentioned. Access to research sites, condition of research sites, transportation and accommodation costs, availability and accessibility of research sites, are amongst some of the widely cited reasons. These issues are largely and generally related to convenience. Samples that are not based on these parameters, may be selected using other parameters such as size of country, population of country, location of country, the level of development of country (Pollit and Bouckaert, 2011), and so on, depending on what will be analysed. Some of these selection parameters, such as access to research sites and accessibility, contribute to the reasons why some countries, particularly developed countries, are well researched, especially when compared with developing or under-developed countries.

When compared with stage one sampling issues, such as selecting countries or societies and organisations, the process of stage two sampling, i.e. sampling within countries or societies, organisations, organisational actors and individuals, is much more complex. When countries or societies are selected based on convenience, for example proximity to the researcher, tourism reasons and other factors such as the parameters identified above, the question that arises is based on what conditions and parameters researchers conduct stage two sampling, i.e. sampling within these countries or societies. In this context, stage two sampling may be some form of probability sampling, when there are many cases to choose from and the complete population set is known. However, when there are only a few cases, which is often the case in comparative studies, there must be some form of rules or methods for coordinating non-probability sampling at this stage, to find a way of improving the reliability and validity of the research process and research findings. However, it is unfortunately usually difficult to coordinate this stage two sampling using some form of rules or methods, making it important for stage one sampling to be theoretical. Nevertheless, it may be possible to generate this stage two sample using theories, especially when theories are very robust.

It is important to note that sampling through theories is more appropriate for stage one sampling (country or society selection), rather than for stage two (within country or society sampling). Notwithstanding, theoretically generating sampling at the initial stage of selecting country or society increases the rigour of comparative studies, even when within country sampling follows some form of purposive sampling. This effectively means that sampling at the stage of selecting countries or societies may represent both purposive and convenience sampling. On the other hand, stage two (within country or society) sampling can only be purposive and cannot include convenience sampling. Therefore, if sampling at the initial stage of country/society/organisation selection can be theoretical, means that convenience sampling will be eliminated at both the country or society selection level (stage one) as well as within country or society level (stage two). Thus, comparative researchers can improve both their own confidence as well as that of observers who rely on their research outcomes.

\subsection{Generating comparative samples from theories}

There are six stages in building comparative samples from theories. The first stage entails the decision about the type of comparative analysis to conduct. After deciding on the type of comparative analysis to conduct, the second stage involves determining the type of comparative design to use. The third stage comprises a rigorous review of literature. The fourth stage consists of generating theoretical arguments from literature. The fifth stage 
requires matching cases, countries or societies with the theoretical arguments derived from the literature to be used in conducting the study, and selecting countries based on the matched countries to theories and other parameters such as closeness, or how well the countries are performing in terms of the theories (provided several countries match a particular theoretical argument). The final stage encompasses stage two sampling, selecting within country or society samples, based on the selected countries or societies, or based on theoretical arguments where applicable. From the above, the stages taken together highlight the embedded transparency inherent in theoretical sampling. An explanation of this kind of sampling method in studies will show the transparency level of how sampling is conducted, as well as when cases emerge rather than just selecting convenient cases. Thus, readers, observers and those who may want to focus on research process are able to note the high level of transparency in the research process.

\subsubsection{Deciding the type of comparative analysis}

There are several types of comparative analyses. In this regard, Glaser and Strauss (1967) asserts that the comparative approach should be seen as an umbrella term as it has fundamental distinctions within it.

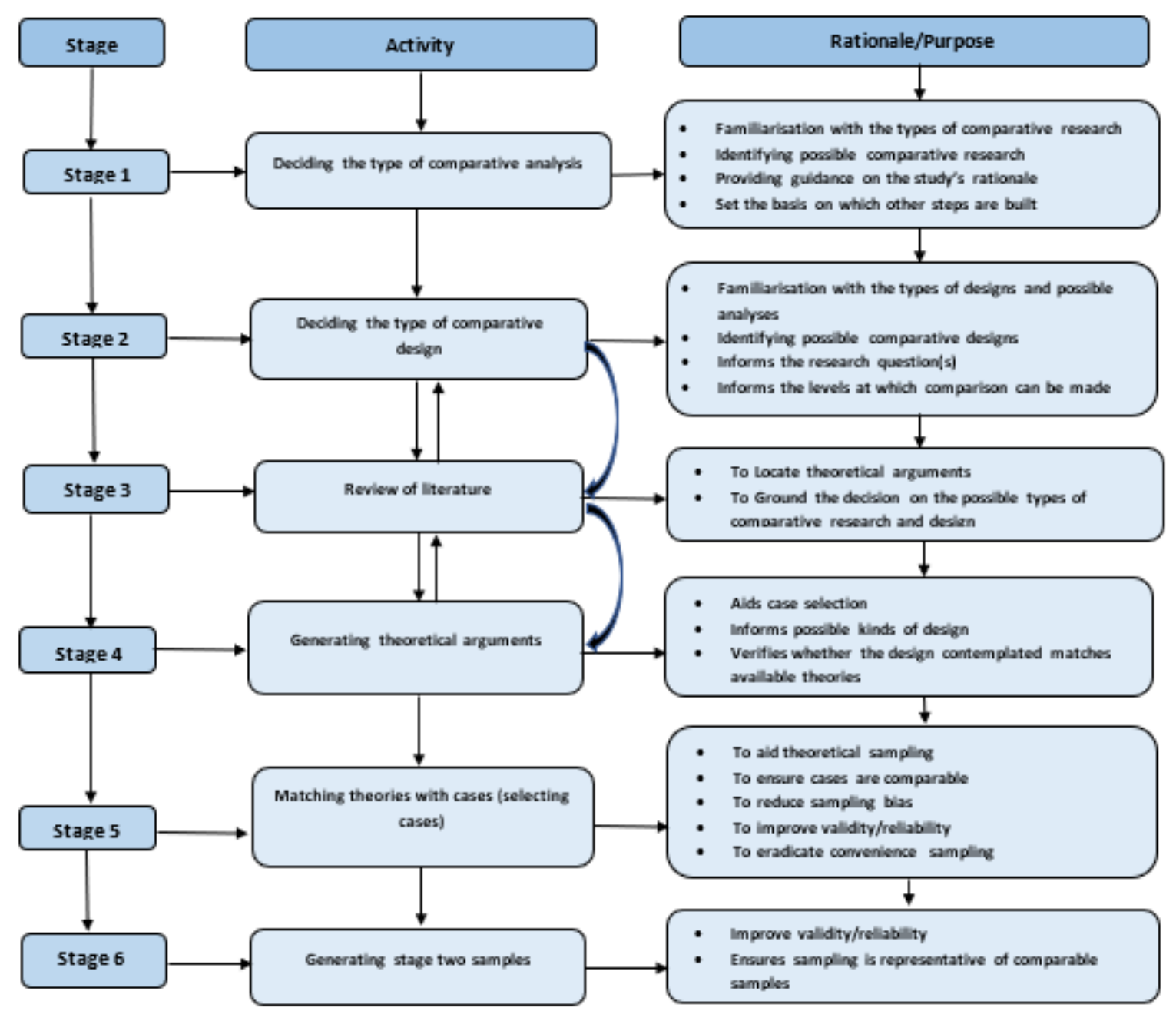

Figure 1: Process of theoretical sampling

The major challenge in grouping comparative studies is caused by the frame of reference used being both synonymous with general comparative research, while also denoting particular forms of comparison (Oyen, 1990). Traditionally, the comparative approach has been grouped into cross-sectional or cross-case, crosscountry, cross-society or cross-national comparative approaches, with other categories or groupings of the comparative approach being arranged under these groups. These other categories include qualitative and quantitative comparative approaches, single- $N$, small- $N$ and large- $N$, as well as inductive and deductive comparative studies (Burnham et al., 2008). Since single $N$ represent a single case, it thus makes sense to theorise that Small- $N$ cases are cases between 2 - 50; while in line with Greckhamer, Misangyi and Fiss (2013), 
large- $N$ are cases above 50 . A cross-sectional comparative approach involves a comparative analysis carried out within a single case study (for example within a single country or organisation).

On the other hand, the cross-national, cross-society or cross-country approach comprises comparative analyses carried out between or among different countries, nations or societies. This category of comparative approach appears to be the main area where comparative analysis is usually employed. Kohn (1989a; 1989b) identifies four types of comparative research: cross-national, transnational, case study comparative and cultural context studies (Harrison and Callan, 2013). These categories may be further classified under four sub-types: nation as the object of study, nation as the context of study, nation as the unit of analysis and transnational comparative study (Kohn, 1989a; 1989b). Countries, nations or societies may therefore be the object of comparative study, in which the researcher is primarily interested in the countries of study and not in testing some hypotheses. Here, the sample selection is usually based on convenience (Harrison and Callan, 2013). The context of the study represents another area where cross-national comparative analysis may be applied. In such instances, the researcher is interested in verifying or generalising research results of the phenomena under study, between or among nations. Thus, countries, nations, or societies are mere cases in which this may be achieved. The unit of analysis is the third type of cross-national research noted by Kohn (1989a; 1989b). The interest of the researcher would be to examine the relationship between the phenomena under study and the features of the countries being studied, with countries simply being reduced to examples along the lines of theoretical arguments. Theoretical arguments therefore regard a nation or an organisation as a context, or a unit of analysis which may be compared and not simply focusing on nations or organisations as mere objects of study. The final type is trans-national, in terms of which nations are treated as elements of a larger international system with a focus on systems, such as developing nations or capitalism.

\subsubsection{Deciding the type of comparative design}

There are basically two types of comparative approach design, categorised as most similar and most different. In addition there is the qualitative comparative approach (QCA) and its variants (Crisp-Set (csQCA) qualitative approach; Multi-value (mvQCA) qualitative approach and Fuzzy Sets (fs QCA) qualitative approach (See Rihoux and De Meur, 2009; Berg-Schlosser et al., 2009; Cronqvist, 2009; Ragin, 2009; Emmenegger, Kvist and Skaaning, 2013; Hug, 2013; Huarng and Roig-Tierno, 2016; Toshkov, 2016). The discussion of these variants of qualitative comparative approach is beyond the scope of this study. It is nevertheless important to note that the choice of approach is based on the most similar and most different designs (Berg-Schlosser et al., 2009). In the context of comparative design, Ragin (2000) notes that the purpose of diversity-oriented research is to bridge two opposing principles of generality and complexity. Further, Smelser (1973) submits positive and negative comparative designs. The positive design is synonymous with the most similar design and the negative is synonymous with the most different design. The essence of using either of these designs is to ensure that research question(s) is closely aligned to the comparative design. In this context, Warwick and Osherson (1973) submit that comparison broadly entails the process of detecting similarities and differences between or among cases. In this way, the most different and the most similar research designs provide the initial basic direction for selecting cases. The design decision informs the questions to be asked and vice versa. At this stage, the comparative researcher accordingly decides on the type of question(s) to pose for the study, which in turn assists in formulating the question(s).

The most similar and most different design is based on the work of Mill (1967), dealing with the method of agreement and method of difference. Mill's (1967) early work has been discussed by a number of authors, including but not limited to Scheuch (1990); Ragin (2000) in discussing practical considerations in studying diversity; George and Bennett (2005); Druckman (2005); Burnham et al. (2008); Berg-Schlosser et al. (2009) and Toshkov (2016). This approach enables the ability to make comparisons in terms of similarities and/or differences, based on possible causal variables and the phenomena being studied (Schutt, 2012). The most similar or method of agreement design entails establishing that cases exhibiting the phenomenon under study, also exhibits a set of causal effects, even though they may vary in other ways that may appear to be causally relevant (Schutt, 2012). On the other hand, the most different or the method of difference relates to a situation where cases do not exhibit common phenomena or causal effects, but may however, agree to some extent on relevant cases (Schutt, 2012). For an overview of method of agreement and method of difference, see Lieberson (1991; 1994) and Anckar (2008).

Although, as noted above, the discussion of the variants of qualitative comparative approach is beyond the scope of this study, it is important to note that most comparative research designs utilise Mill's methods of difference 
or agreement (Anckar, 2008). QCA is a case-oriented method (Anckar, 2008) that draws on Mill's methods of difference and agreement. In this way, cases are usually selected based on whether a study seeks to make comparisons based on similarities and/or differences.

In addition, a decision should to be made on whether the study will focus on a single- $N$ case, small- $N$ cases or large- $N$ cases. Even though it appears to have been argued that comparative large- $N$ analysis can only be conducted mathematically, experimentally and statistically (Lieberson, 1994; Anckar, 2008), large- $N$ qualitative and mixed methods comparative analysis is possible where large databases are available (O'Toole and Meier, 2017; Greckhamer et al., 2018). It appears the reason why large- $N$ cases analyses are usually not attempted using the comparative approach may be because comparative questions especially in sociology, organisational economics and public management are usually questions of boundary and relation (Peters, 1994) posed to confirm or determine differences and/or similarities in different national, organisational and individual boundaries. In such cases, large- $N$ cases comparative analyses are usually not possible. The reason why the comparative approach is more suitable for small- $N$ is because it usually starts with cases in order to learn from the cases (Toshkov, 2016). However, following Toshkov's (2016) observation that the comparative approach rests on two scenarios, large- $N$ analysis is also possible. The first starts with a research question and questions the impact of variable $x$ (for example the type of government) on outcome $y$ (for example, the kind of intervention, say free medication)? The second scenario starts with a set of cases and questions what can be learnt from the cases. While the second scenario will no doubt only support small- $N$ analysis (Thomann and Maggetti, 2020), the first scenario shows that large- $N$ comparative analysis is possible, although this is contingent on the availability of large databases, and should questions permit, and whether it is possible to design an experiment when there are no large databases as well as theoretically relevant cases. This in effect means that it is possible to conduct large- $N$ comparative organisational, national and international analyses where there are databases that can be used for qualitative analysis. Thus, when there are large databases, as with quantitative experimental research that can be conducted at micro, meso and macro levels with administrators, qualitative archival analysis is possible using database records.

The decision at this stage is based on ensuring that the researcher is aware of the possible designs and analyses, before embarking on the review of literature. Even though the design is carried out at this stage, nothing is guaranteed until after completing the next two stages, the literature review and the generation of theoretical arguments, since the researcher will have to revisit this stage after the subsequent two stages. This in effect sustains that even though feedback and feedforward loops apply to the sampling process discussed in this paper, feedback and feedforward loops are more applicable at the stage of deciding the type of comparative design, review of literature and generating theoretical arguments, as illustrated in Figure 1.

\subsubsection{Rigorous literature review}

Having decided on the type of comparative analysis and the design of the comparative analysis, the next stage is to review literature on the subject matter. This stage appears to be the most challenging stage, because, as with the main objective of reviewing literature to locate the research gap, the researcher is also looking for patterns, arguments and rival arguments that could be used for the purposes of sampling. The main challenge here is that it immediately becomes apparent that not all theoretical arguments can be used in generating samples. It therefore follows that the researcher will have to employ some form of method to arrive at the theoretical arguments that may inform case selection. The idea is to document all seemingly important arguments as well as counter arguments, because it is likely that in a situation where there are no sound theoretical arguments, documented theoretical arguments will have to be combined in order to arrive at theories that will enable case selection. In addition, even though there may be sound theoretical arguments, the researcher may have to refine these arguments further to permit stage one and stage two sample selection. One of the ways of conducting this type of literature review is by researching seminal works on a subject area, before moving to more recent research. This will ensure that seminal arguments are documented, as seminal arguments are mostly useful in theoretical sampling.

\subsubsection{Generating theoretical arguments from literature}

Theoretical arguments are derived from the literature review stage described above. Since to a large extent, the type of theoretical arguments derived informs the type of design that may be used, the first step is to establish whether the type of research design is applicable for the derived theoretical arguments. However, when following theory generation from literature, it may only be possible to carry out a most similar analysis and not a most different analysis, and vice versa. In some cases, theoretical arguments may permit both most similar 
and most different analyses, providing the researcher with some form of decisional autonomy regarding the type of analysis to conduct. In essence, after completing this step, the researcher will have to go back to the second step, deciding the type of comparative design, in order to check whether there is a need to use some form of design, other than the one decided at that stage. However, while it may be argued that the research design step should come after the generation of theoretical arguments, it is important for the researcher to think about the design at that early stage, to look out for patterns of design, while engaging in the review of literature.

\subsubsection{Matching theories with cases (selecting cases)}

Good theoretical arguments allow researchers some form of autonomy in the choice of selecting the cases to work with. This is because patterns and features of the theoretical arguments will be present in so many cases, be it nations, organisations and organisational actors. Where this is possible, the researcher is able to select cases taking into account the three selection criteria formulated by Burnham et al. (2008), and select cases that maximise comparative/experimental variance, minimise error variance and control extraneous variance. Moreover, being satisfied that theoretical arguments are applicable to a number of cases, the researcher is able to select stage two samples/cases based on some form of purpose/convenience (be it for the purposes of confirming, disconfirming, or generalising) in terms of closeness to research sites and research participants, the level of development of countries, the features of theoretical arguments displayed by countries in terms of how well a country/organisation is thriving on a theory; as well as based on the all-important issue of where new knowledge can be generated amongst the identified cases. However, in executing this, the researcher should be careful to avoid powering personal interest into the process. Taken together, the three selection criteria and carefully matching theoretical arguments to cases reduce theoretical sampling bias.

\subsubsection{Generating stage two samples from theories}

This stage entails selecting samples within country or society, and within organisations based on the selected countries or societies, from stage one samples based on theoretical arguments. While it may not be possible to sample theoretically in stage two sampling, it can nevertheless be attempted. The feasibility is highly contingent on whether or not theories obtained from literature are robust enough and may be applied to both stage one and stage two sampling. However, even though it may not be possible, purposive sampling can be applied in stage two, provided that stage one sampling has been based on some form of theoretical sampling. Theoretical sampling is important in the first stage because the population contains the set of countries, organisations and units (Eisenhardt, 1989), from which stage two sampling is to be derived. Some authors (Eisenhardt, 1989; Caronna, Pollack and Scott, 2009; Wiesel and Modell, 2014; Dai et al., 2016) have treated purposive sampling as theoretical sampling (see Eisenhardt, 1989 in discussing Glaser and Strauss (1967) and Harris and Sutton's (1986) study on dying organisations), in which cases were selected based on the purpose of the research. For example, a study focusing on the Open source community, and in which any four projects (cases) at different stages were selected in order to examine organisational practices (see Chen and Mahony, 2009), appears to be purposive and not theoretical. Even though it may appear that stage two sampling can only be conducted purposively, it is worthwhile for researchers to match cases cognisant of the dimensions to which cases can be argued to be comparable, most similar and most different. For example, in terms of sectoral, departmental and ownership, in order to reduce the limitations of comparative analysis.

\subsection{Evaluating the usable theories}

It appears not all theoretical arguments can be used for generating comparative analysis samples, or lead to matching samples. This gives rise to the question: how do researchers then evaluate whether theories are useful or not, and therefore evaluate those usable theories? The best way of doing this may be to ensure that the theoretical lenses to be used, are based on some form of known theoretical arguments in a particular field of research. This does not however, mean that theoretical arguments that are less known cannot be applied. It simply means that observers, especially those within a particular field, who are grounded in the literature on a particular subject, are more likely to place reliance on the research process, thereby also trusting the research outcomes.

Irrespective of whether a theory is a well-established theory or not, another important factor is to ensure that cases are carefully selected based on the emerging theory or theories, especially when there are a number of applicable cases, of which researchers need only a few. Convenience/purposive selection of both stage one and stage two samples, where there are many matching cases, should only be applied to a limited extent with selection instead being based on other carefully thought out parameters; otherwise, the theoretical sampling 
rationale will be lost, and sampling will be based on convenience sampling rather than some form of theoretical sampling.

Table 1 illustrates bad and good practices in comparative sampling as well as goals that can be achieved through shifting to and embracing theoretical sampling. The table also, although studies may not fit perfectly, attempted to identify some studies that may be argued to have features of good practices in line with the reasonings in each of the six stages of the theoretical sampling process.

Table 1: Good practices in comparative sampling in business and organisational research

\begin{tabular}{|c|c|c|c|c|}
\hline $\begin{array}{l}\text { Theoretical } \\
\text { sampling } \\
\text { stage }\end{array}$ & Bad practice & Good practice & $\begin{array}{l}\text { Shifting to good } \\
\text { practice/goal achieved } \\
\text { through good practice }\end{array}$ & $\begin{array}{l}\text { Studies featuring good } \\
\text { practice }\end{array}$ \\
\hline $\begin{array}{l}\text { (1- Deciding } \\
\text { the type of } \\
\text { comparative } \\
\text { analysis) }\end{array}$ & $\begin{array}{l}\text { Not specifying the } \\
\text { type of } \\
\text { comparative } \\
\text { research/analysis. }\end{array}$ & $\begin{array}{l}\text { Specifying the } \\
\text { type of } \\
\text { comparative } \\
\text { research/analysis. }\end{array}$ & $\begin{array}{l}\text { Aids familiarisation } \\
\text { with the types of } \\
\text { comparative research, } \\
\text { identification of } \\
\text { possible comparative } \\
\text { research and provision } \\
\text { of guidance on study's } \\
\text { rationale. }\end{array}$ & 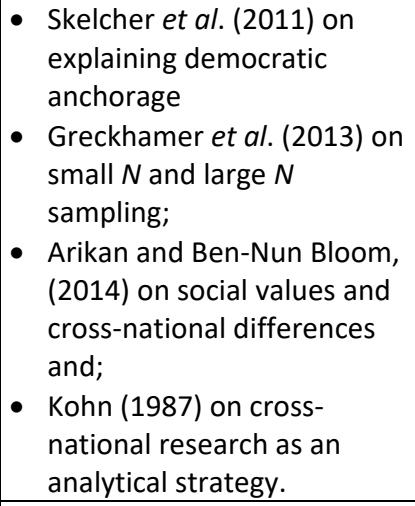 \\
\hline $\begin{array}{l}\text { (2-Deciding } \\
\text { the type of } \\
\text { comparative } \\
\text { design) }\end{array}$ & $\begin{array}{l}\text { Not specifying the } \\
\text { type of } \\
\text { comparative } \\
\text { design. }\end{array}$ & $\begin{array}{l}\text { Specifying the } \\
\text { type of } \\
\text { comparative } \\
\text { design. }\end{array}$ & $\begin{array}{l}\text { Aids familiarisation } \\
\text { with the types of } \\
\text { design and possible } \\
\text { analyses, identification } \\
\text { of possible comparative } \\
\text { designs, developing the } \\
\text { research questions, } \\
\text { deciding the levels at } \\
\text { which comparison can } \\
\text { be made. }\end{array}$ & $\begin{array}{l}\text { - Anckar (2008) on the } \\
\text { application of the most } \\
\text { similar and the most } \\
\text { different systems design in } \\
\text { comparative analysis. } \\
\text { - Lacey and Fiss (2009) on } \\
\text { QCA; } \\
\text { - Mahalingam, Devkar and } \\
\text { Kalidindi (2011) on QCA } \\
\text { and; } \\
\text { - Gligor et al. (2020) on QCA. }\end{array}$ \\
\hline $\begin{array}{l}\text { (3-Review of } \\
\text { literature) }\end{array}$ & $\begin{array}{l}\text { Staring studies } \\
\text { with research } \\
\text { questions and } \\
\text { case selection } \\
\text { rather than prior } \\
\text { review of } \\
\text { literature. }\end{array}$ & $\begin{array}{l}\text { Reviewing } \\
\text { literature so as to } \\
\text { document } \\
\text { theoretical } \\
\text { arguments } \\
\text { following the } \\
\text { identification of } \\
\text { the type of } \\
\text { comparative } \\
\text { research. }\end{array}$ & $\begin{array}{l}\text { Aids locating } \\
\text { theoretical arguments } \\
\text { as well as grounding } \\
\text { the decision on the } \\
\text { possible types of } \\
\text { comparative research } \\
\text { and design. }\end{array}$ & $\begin{array}{l}\text { - Bromley, Hwang and Powell, } \\
\text { (2012) on decoupling; } \\
\text { - Aversa, Furnari and } \\
\text { Haefliger (2015) on QCA } \\
\text { and; } \\
\text { - Russo and Cofente (2019) } \\
\text { on QCA. }\end{array}$ \\
\hline $\begin{array}{l}\text { (4- } \\
\text { Generating } \\
\text { theoretical } \\
\text { arguments) }\end{array}$ & $\begin{array}{l}\text { Generating } \\
\text { theoretical } \\
\text { arguments from } \\
\text { cases } \\
\text { and/outcomes. }\end{array}$ & $\begin{array}{l}\text { Generating } \\
\text { theoretical } \\
\text { arguments from } \\
\text { literature. }\end{array}$ & $\begin{array}{l}\text { Aids selection of cases, } \\
\text { possible kinds of } \\
\text { design, verifying } \\
\text { whether the design } \\
\text { contemplated matches } \\
\text { available theories. }\end{array}$ & $\begin{array}{l}\text { - Filatotchev, Toms and } \\
\text { Wright (2006) on theoretical } \\
\text { arguments supported by } \\
\text { empirical data and; } \\
\text { - Bohórquez Arévalo and } \\
\text { Espinosa (2015) on } \\
\text { theoretical approaches. } \\
\end{array}$ \\
\hline $\begin{array}{l}\text { (5- Matching } \\
\text { theories with } \\
\text { cases } \\
\text { (selecting } \\
\text { cases)) }\end{array}$ & $\begin{array}{l}\text { Selecting weak } \\
\text { theoretical } \\
\text { arguments that } \\
\text { are not robust } \\
\text { enough to enable } \\
\text { proper case } \\
\text { matching. }\end{array}$ & $\begin{array}{l}\text { Selecting robust } \\
\text { theoretical } \\
\text { arguments that } \\
\text { have patterns and } \\
\text { features in many } \\
\text { cases and allow } \\
\text { for the selection } \\
\text { of good cases. }\end{array}$ & $\begin{array}{l}\text { Aids theoretical } \\
\text { sampling, ensuring } \\
\text { cases are comparable, } \\
\text { reducing sampling bias, } \\
\text { improving reliability } \\
\text { and validity and } \\
\text { eradicating } \\
\text { convenience sampling. }\end{array}$ & $\begin{array}{l}\text { - Filatotchev, Toms and } \\
\text { Wright (2006) on theoretical } \\
\text { arguments supported by } \\
\text { empirical data; } \\
\text { - Greckhamer et al. (2013) on } \\
\text { small } N \text { and large } N \\
\text { sampling and; }\end{array}$ \\
\hline
\end{tabular}




\begin{tabular}{|l|l|l|l|l|}
\hline $\begin{array}{l}\text { Theoretical } \\
\text { sampling } \\
\text { stage }\end{array}$ & Bad practice & Good practice & $\begin{array}{l}\text { Shifting to good } \\
\text { practice/goal achieved } \\
\text { through good practice }\end{array}$ & $\begin{array}{l}\text { Studies featuring good } \\
\text { practice }\end{array}$ \\
\hline & & & $\begin{array}{l}\text { Bohórquez Arévalo and } \\
\text { Espinosa (2015) on } \\
\text { theoretical approaches. }\end{array}$ \\
\hline $\begin{array}{l}\text { Generating } \\
\text { stage two } \\
\text { samples) } \\
\text { one and stage two } \\
\text { sampling based } \\
\text { on convenience } \\
\text { sampling. }\end{array}$ & $\begin{array}{l}\text { Selecting stage } \\
\text { two samples from } \\
\text { theoretically } \\
\text { sampled stage } \\
\text { one samples. }\end{array}$ & $\begin{array}{l}\text { Aids improving } \\
\text { reliability and validity, } \\
\text { ensuring sampling is } \\
\text { representative of } \\
\text { comparable samples. }\end{array}$ & $\begin{array}{l}\text { - Bohórquez Arévalo and } \\
\text { Espinosa (2015) on } \\
\text { theoretical approaches; } \\
\text { Filatotchev, Toms and } \\
\text { Wright (2006) on theoretical } \\
\text { arguments supported by } \\
\text { empirical data; }\end{array}$ \\
& $\begin{array}{l}\text { Selecting stage } \\
\text { Misangyi et al. (2016) on } \\
\text { causal complexity and; } \\
\text { Ordanini, Parasuraman } \\
\text { and Rubera (2013) on QCA } \\
\text { of service innovation } \\
\text { configurations. }\end{array}$ \\
\hline
\end{tabular}

\subsubsection{Comparison with other sampling techniques}

The sampling procedure discussed here is similar to that proposed by other commentators, albeit with notable differences. For example, in discussing this sampling method, this paper has drawn on Glaser and Strauss's (1967) comparative analysis assessment and theoretical sampling; Ragin's (1987) qualitative comparative approach; Eisenhardt's (1989) discussion of Glaser and Strauss' (1967) theoretical sampling; Peters' (1994) theoretical and comparative case study; Ragin's (2000) arguments of diversity-oriented research, which is informed by case-oriented research; Druckman's (2005) focused case comparison, George and Bennett's (2005) method of structured, focused comparison and Yin's (2014) analytic generalisation, as well as literal and analytical replication. Nevertheless, the approach discussed here exhibits notable differences in a number of dimensions compared with previous works. In this connection, firstly, even though this paper touches on other aspects, the approach discussed here is concerned with generating stage one and stage two samples from theories for any form of comparative analysis. Of previous works, the closest to the approach described here is that of Glaser and Strauss (1967), Ragin's (2000) arguments of diversity-oriented research, which is informed by case-oriented research and George and Bennett's (2005) method of structured, focused comparison. Glaser and Strauss' (1967) theoretical sampling entails a process of data collection in which the researcher collects, codes and analyses data for the purpose of deciding the kind of data to collect following analysis of data collected at the initial stage with the aim of developing theory. Thus, the theoretical sampling described by Glaser and Strauss (1967) is basically concerned with deciding on the groups or subgroups from which case study data can be re-collected for the purposes of generating theory. The two characteristics of George and Bennett's (2005) method of structured, focused comparison are structured and focused. It is "structured" since it starts with researchers posing general questions that are in line with the research objective. These questions are then used in making sense of each case under study as a guide as well as to standardise data collection, thereby making systematic comparison and cumulation of the findings of the cases possible. Further, it is "focused" because in that it deals specifically with certain research objective aspects of the historical cases examined, as well as an appropriate theoretical focus for such objective. While the starting point in George and Bennett's (2005) method of structured, focused comparison is the research question, it is under stage two - deciding the type of comparative design - in the theoretical sampling discussed in this paper. Yin's (2014) analytic generalisation is based on either corroborating, modifying, rejecting, or otherwise advancing theoretical concepts noted in designing case study or new concepts that arose upon the completion of case study. It appears analytic generalisation, compared to theoretical sampling discussed here, is not employed for the purposes of sample selection, but only for theoretical corroboration, modification and rejection. Yin's (2014) literal replication entails selecting two (or more) cases that are predicted to produce similar findings within a multiple-case study, while theoretical replication entails selecting two (or more) cases that are predicted to have contrasting findings in a multiple-case study. While these, especially theoretical replication, are close to the theoretical sampling discussed here, as noted by Yin (2014), research questions inform the selection of cases for literal replication, while in theoretical replication, cases are selected based on examples of outcomes which inform the number and types of theoretical replications to be covered in a study. Similarly, Ragin's (2000) discussion of comparative study informed by diversity-oriented research indicates that the starting point in the comparative study 
described is case selection. Case selection is a later stage step (stage four) in the theoretical sampling discussed here. In this regard, Ragin (2000) posed an important question (under discussion of the features of diversityoriented research borrows from case-oriented research), when cases are selected - "what are they cases of?" Under the theoretical sampling discussed here, cases used are cases of theoretical arguments rather than cases of outcomes and questions. As with these authors, the theoretical case study described by Peters (1994) is close to what is intended, but a theoretical case study is not driven by theoretical formulations, but rather it applies the same methodology and the same research questions on different cases with the aim of inducing generalities from the findings. Druckman's (2005) focused case comparison entails matching cases for comparison purposes. Ragin's (1987) qualitative comparative approach attempts to combine qualitative (case-oriented) and quantitative (variable-oriented) techniques so as to ensure that systematic conceptualised case comparison is possible. In contrast to these authors, in this paper, sampling theoretically entails generating stage one and stage two samples from theoretical arguments. As such, it differs from, but complements Glaser and Strauss' (1967) theoretical sampling, Ragin's (1987) qualitative comparative approach, Eisenhardt's (1989: 536-537) discussion of Glaser and Strauss (1967) theoretical sampling, Peters' (1994) theoretical case study, Ragin's (2000) discussion of comparative study informed by diversity-oriented research, George and Bennett's (2005) method of structured, focused comparison, Druckman's (2005) focused case comparison. However, the approach is similar to and complements Yin's (2014) analytic generalisation as well as literal and analytical replication.

Secondly, the approach discussed here contributes new ideas. Authors such as Glaser and Strauss (1967), Druckman (2005) and Schutt (2012), have argued differently on the starting point of a comparative study. Whereas Druckman (2005) submits that the starting point is the specification of variables, Schutt (2012) argues that the starting point should be the specification of the theoretical framework while identifying useful concepts and events, and Glaser and Strauss (1967) emphasise data collection as the starting point. The idea here is that the starting point should be informed by the decision on what type of comparative study to embark on. In this connection, Druckman (2005) usefully notes that comparative analysis inquiry is usually a later stage analysis. Accordingly, the issue of specification of variables and theoretical frameworks, and data collection are typically decisions taken at later stages of the research, rather than as a starting point. In this regard, this study has provided a six-stage process towards generating samples from theoretical arguments.

Thirdly, the approach discussed here has highlighted that purposive sampling has often been mistaken as theoretical sampling. The difference being that some approaches leading to purposive sample selection are based on the purpose of study, rather than on theoretical arguments. An example of this is the Warwick study (Pettigrew, 1973) discussed by Eisenhardt (1989), in which a case was selected based on a successful firm performance and the other case based on an unsuccessful firm performance. In this situation, theoretical sampling would have been sampling based on some form of theoretical arguments. Say, for the purpose of illustration, that state-owned enterprises should be organised in such a way that commercial objectives are separated from social objectives, thus, these state-owned enterprises should not be organised under state ministries (see Keynes (1926) for this argument). A rival argument is that state-owned enterprises should be organised under the state, so as to provide a form of competition necessary to curtail the evils of private ownership (see Marx (1967) for this argument); in such an instance selecting samples of countries and organisations within the countries would be based on these theoretical arguments. Another example is that successful firms pay more attention to organisational culture and less successful firms do not (see Morgan (2006) and Naranjo-Valencia, Jimenez-Jimenez and Sanz-Valle (2017) for such argument). A rival theory argues that successful firms pay attention to human and capital knowledge (see Jalal, Toulson and Tweed, (2011) and Kozielski (2016) for such argument); thereby, selecting samples based on these arguments.

Finally, the approach has shown that even though stage two case selection is based on purposive sampling, reliability and validity issues are less problematic when stage one sampling follows some form of theoretical sampling. The idea being that stage one sampling is arguably more important compared with stage two sampling in that stage two samples are derived from stage one samples.

\section{Conclusion}

While it has been relatively easy to argue that sampling and improving research rigour has historically been one of the major challenges of the comparative research approach (Thomann and Maggetti, 2020), it has been far more difficult to proffer solutions to these problems. Within this context, this paper aims to bridge this gap by offering a six-stage process for theoretical sampling. Thus, the main purpose of this article is to describe how to 
generate comparative sampling from theoretical arguments. In this regard, this paper has adopted a two-phase process involving six steps to demonstrate how this may be achieved. It is submitted that the strengths of the approach may be applied by researchers conducting comparative analysis. While this approach may proffer some new insights, it builds on the work of other authors on data collection and sampling. As a result, the prior research, which sets the basis for the approach discussed here, may also be useful where the application of this approach is not possible. Moreover, as Druckman (2005) rightly observes, since the comparative analysis occurs at later stages of the research process, the starting point in early work becomes useful at later stages of comparative analysis, especially when the focus of the analysis is on generating, and not verifying theories (Huarng and Roig-Tierno, 2016). In this way, this approach taken singularly or together with earlier works, is expected to assist researchers generally, especially accounting and business researchers interested in public sector accounting, which is usually some form of sociological, organisational economics and public management comparative analyses, in conducting comparative research that can withstand research observers' as well as reliability and validity tests. While qualitative researchers may utilise other sampling techniques, it is believed that the theoretical sampling approach discussed here ensures validity and reliability.

\section{Future research}

Even though this paper has tried as much as possible to comprehensively describe theoretical sampling for comparison thereby offering insights as to how theoretical sampling improves validity, transparency and can be conducted, this paper may not have covered all the relevant issues and aspects of theoretical sampling. In addition, although this paper has described a theoretical sampling process, it was utilised to select samples for a PhD thesis from which it was obvious that the sampling approach provided significant advantages over the more traditional sampling approaches employed by comparative researchers. In this context, future research is required to further exemplify this theoretical sampling process. Future research could also build on this sampling process to argue that the sampling approach described here supports experimental design since it has been argued that experimental research is a comparative activity and that usually, the purpose of doing the experiments is to compare two or more ways of doing something (Easterling, 2015). This kind of research will have to document how this theoretical sampling may improve experimental research as well as the process that will be involved.

Although the discussion here may be applied to quantitative analysis, it's discussion in this paper has been more in line with application to qualitative comparative analysis. Future research could develop aspects of this paper that are relevant to quantitative research. In this instance, interested researchers will have to review additional sampling literature applicable to quantitative research.

Future research may also consider the sampling approach described here on small and large $N$ cases to document whether the approach works better with small cases or with large cases. In this instance, researchers should, in the process of their study, document whether any form of difficulty is encountered in matching cases (small or large $N$ ) to theoretical samples. Findings from such study, especially those in which small cases and large cases are used in testing the same theoretical argument, will be worthwhile as it will indicate whether or not results change when sample size increases and if so, to what extent. Furthermore, such a study will be useful in establishing whether or not large $N$ increases generalisability, since Thomann and Maggetti (2020) have argued that large $N$ cases alone do not equate to generalisability.

Future research could further explore comparing outcomes in respect of different sampling method; for example, Ordanini, Parasuraman and Rubera (2014) and Russo et al., (2019) show the differences between symmetric (MRA) and asymmetric method (QCA).

A future line of research could also explore documenting matching between case studies and QCA with interviews (Forkmann, Henneberg, Witell and Kindström, 2017).

\section{References}

Aldrich, H.E., 2009. Lost in space, out of time: why and how we should study organizations comparatively. Research in the Sociology of Organizations, 26, pp.21-44.

Allardt, E., 1990. Challenges for comparative social research. Acta Sociologica, 33(3), pp.183-193.

Anckar, C., 2008. On the applicability of the most similar systems design and the most different systems design in comparative research. International Journal of Social Research Methodology, 11(5), pp.389-401. 
Arikan, G. and Ben-Nun Bloom, P., 2014. Social values and cross-national differences in attitudes towards welfare. Political Studies, 63(2004), pp.431-448.

Aversa, P., Furnari, S. and Haefliger, S., 2015. Business model configurations and performance: a qualitative comparative analysis in Formula One racing, 2005-2013. Industrial and Corporate Change, 24: pp.655-676.

Barzelay, M. and Gallego, R., 2010. The comparative historical analysis of public management policy cycles in France, Italy, and Spain: symposium introduction. Governance, 23(2), pp.209-223.

Berg-Schloser, D. and De Meur, G., 2009. Comparative research design: case and variable selection. In: B. Rihoux and C.C. Ragin, eds. Configurational comparative methods: qualitative comparative analysis (QCA) and related techniques. pp.20-32. California: Sage Publications, Inc.

Berg-Schlosser, D., De Meur, G., Rihoux, B. and Ragin, C.C., 2009. Qualitative comparative analysis (QCA) as an approach. In: B. Rihoux and C.C. Ragin, eds. Configurational comparative methods: qualitative comparative analysis (QCA) and related techniques pp.1-18. California: Sage Publications, Inc.

Bohórquez Arévalo, L.E. and Espinosa, A., 2015. Theoretical approaches to managing complexity in organizations: a comparative analysis. Estudios Gerenciales, 31(134), pp.20-29.

Bromley, P., Hwang, H. and Powell, W.W., 2012. Decoupling revisited: common pressures, divergent strategies in the U.S. nonprofit sector.M@n@gement, 15, pp.468-501.

Burnham, P., Lutz, K.G., Grant, W. and Zig, L.H., 2008. Research methods in politics. 2nd ed. New York: Palgrave Macmilian.

Caronna, C.A., Pollack, S.S. and Scott, W.R., 2009. Organizations, populations, and fields: investigating organizational heterogeneity through a multilevel case study design. Research in the Sociology of Organizations, 26, pp.249-270.

Chen, K.K. and O'Mahony, S., 2009. Differentiating organizational boundaries. studying differences between organizations. Comparative Approaches to Organizational Research, 26, pp.183-220.

Cronqvist, L., 2009. Multi-Value QCA (mvQCA). In: B. Rihoux and C. C. Ragin eds. Configurational comparative methods: qualitative comparative analysis (QCA) and related techniques. pp.69-86. California: Sage Publications, Inc.

Dai, N.T., Tan, Z.S., Tang, G. and Xiao, J.Z., 2016. IPOs, institutional complexity, and management accounting in hybrid organisations: a field study in a state-owned enterprise in China. Management Accounting Research, 36, pp.1-22.

Damrosch, D., 2013. Comparative literature? Modern Language Association of America, 18(2), pp.326-330.

Druckman, D., 2005. Doing research : methods of inquiry for conflict analysis. California: Sage Publications, Inc.

Easterling, R.G., 2015. Fundamentals of statistical experimental design and analysis. Chichester: John Wiley \& Sons Ltd.

Eisenhardt, K.M., 1989. Building theories from case study research. Academy of Management Review, 14(4), pp.532-550.

Emmenegger, P., Kvist, J. and Skaaning, S.-E., 2013. Making the most of configurational comparative analysis: an assessment of QCA applications in comparative welfare-state research. Political Research Quarterly, 66(1), pp.185190.

Fainshmidt, S., Witt, M.A., Aguilera, R.V. and Verbeke, A., 2020. The contributions of qualitative comparative analysis (QCA) to international business research. Journal of International Business Studies, 51(4), pp.455-466.

Filatotchev, I., Toms, S. and Wright, M., 2006. The firm's strategic dynamics and corporate governance life-cycle. International Journal of Managerial Finance, 2(4), pp.256-279.

Forkmann, S., Henneberg, S.C., Witell, L. and Kindström, D., 2017. Driver configurations for successful service infusion. Journal of Service Research, 20(3), pp. 275-291.

George, A.L. and Bennett, A., 2005. Case studies and theory development in the social sciences. Cambridge, MA: Harvard University Press.

Glaser, B. and Strauss, A., 1967. The discovery of Grounded Theory: strategies for qualitative research. New York: Aldine.

Gligor, D., Feizabadi, J., Russo, I., Maloni, M.J. and Goldsby, T.J., 2020. The triple-a supply chain and strategic resources: developing competitive advantage. International Journal of Physical Distribution and Logistics Management, 50(2), pp.159-190.

Greckhamer, T., Furnari, S., Fiss, P.C. and Aguilera, R.V., 2018. Studying configurations with qualitative comparative analysis: best practices in strategy and organization research. Strategic Organization, 16(4), pp.482-495.

Greckhamer, T., Misangyi, V.F. and Fiss, P.C., 2013. The two QCAs: from a small-N to a large-N set theoretic approach. In: P.C. Fiss, B. Cambré and A. Marx eds. Configurational theory and methods in organizational research (Research in the Sociology of Organizations, Vol. 38), Bingley: Emerald Group Publishing Limited. pp.49-75.

Guta, A.J., 2013. Comparative analysis of public management in Romania and EU countries. Annals of the University of Petroşani, Economics, 13(2), pp.85-92.

Harris, S.G. and Sutton, R.I., 1986. Functions of parting ceremonies in dying organizations, The Academy of Management Journal, 29(1), pp.5-30.

Harrison, L. and Callan, T., 2013. Key research concepts in politics and international relations. London: Sage Publications, Inc.

Huarng, K.-H. and Roig-Tierno, N., 2016. Qualitative comparative analysis, crisp and fuzzy sets in knowledge and innovation. Journal of Business Research, 69(11), pp.5181-5186.

Hug, S., 2013. Qualitative comparative analysis: how inductive use and measurement error lead to problematic inference. Political Analysis, 21(2), pp.252-265.

Jalal, H.A., Toulson, P. and Tweed, D., 2011. Exploring employee perceptions of the relationships among knowledge sharing capability, organisational culture and knowledge sharing success: their implications for HRM practice. Proceedings of the 8th International Conference on Intellectual Capital, Knowledge Management and Organisational Learning, Vol. 1 and 2, pp.639-646. 
Johns, G., 2001. In praise of context. Journal of organizational behavior, 42, pp.31-42.

Jreisat, J., 2012. Globalism and comparative public administration. New York: Routledge.

Keynes, J.M., 1926. The end of laissez-faire. London: Leonard \& Virginia Woolf.

King, B.G., Felin, T. and Whetten, D.A., 2009. Comparative organizational analysis: An introduction. Research in the sociology of organizations, 26, pp.3-19.

Kohn, M.L., 1987. Cross-national research as an analytic strategy: American Sociological Association, 1987 Presidential Address, American Sociological Association, 52(6), pp.713-731.

Kohn, M.L., 1989a. Cross-national research as an analytic strategy. In: M.L. Kohn ed. Cross-national research in sociology. California: Sage Publications, Inc. pp.77-102.

Kohn, M.L., 1989b. Introduction. In: M. L. Kohn ed. Cross-national research in sociology. California: Sage Publications, Inc. pp.17-31

Kozielski, R., 2016. Determinants of business success - theoretical model and empirical verification. Folia Oeconomica Stetinensia, 16(1), pp.274-285.

Lacey, B. and Fiss, P.C., 2011. Comparative organizational analysis across multiple levels: a set-theoretic approach. In: studying differences between organizations: comparative approaches to organizational research. Research in the Sociology of Organizations, 26 pp. 91-116.

Lieberson, S., 1991. Small N's and big conclusions: an examination of the reasoning in comparative studies based on a small number of cases. Social Forces, 70(2), pp.307-320.

Lieberson, S., 1994. More on the uneasy case for using Mill-type methods in small-N comparative studies. Social Forces, 72(4), pp.1225-1237.

Lincoln, Y.S. and Guba, E., 1985. Naturalistic inquiry. California: Sage Publications Ltd.

Mahalingam, A., Devkar, G.A. and Kalidindi, S.N., 2011. A comparative analysis of public- private partnership (PPP) coordination agencies in India: what works and what doesn't. Public Works Management \& Policy, 16, pp.341-372.

Mahoney, J., 2004. Comparative-historical methodology. Annual Review of Sociology, 30(1), pp.81-101.

Martinus, K. and Hedgcock, D., 2015. The methodological challenge of cross-national qualitative research: comparative case study interviews in Australia and Japan. Qualitative Research Journal, 15(3), pp.373-386.

Marx, K. (1967). Capital: A critique of political economy. New York: International Publishers.

Miles, M. B., \& Huberman, A. M. (1994). Qualitative data analysis: an expanded sourcebook. California: Sage.

Mill, J.S., 1967. A system of logic: rationcinative and inductive. Toronto: University of Toronto Press.

Misangyi, V.F., Greckhamer, T., Furnari, S., Fiss, P.C., Crilly, D. and Aguilera, R., 2016. Embracing causal complexity: the emergence of a neo-configurational perspective. Journal of Management, 43(1), pp.255-282.

Morgan, G., 2006. Images of Organisation. California: Sage Publications, Inc.

Morse, J. M., Barrett, M., Mayan, M., Olson, K., and Spiers, J., 2002. Verification strategies for establishing reliability and validity in qualitative research. International Journal of Qualitative Methods, 1(2), pp. 13-22.

Naranjo-Valencia, J.C., Jimenez-Jimenez, D. and Sanz-Valle, R., 2017. Impact of organisational culture on new product success: an empirical study of Spanish firms. European Management Review, 14, pp.377-390.

O’Toole, J. and Meier, K.J., 2017. Comparative public management: a framework for analysis. In: comparative public management. Washington DC: Georgetown University Press.

Ordanini, A., Parasuraman, A. and Rubera, G., 2014. When the recipe is more important than the ingredients: a Qualitative Comparative Analysis (QCA) of service innovation configurations. Journal of Service Research, 17(2), pp.134-149.

Oyen, E., 1990. The imperfection of comparisons. In: E. Oyen. ed. Comparative methodology: theory and practice in international social research. London: Sage Publications, Inc. pp.1-18.

Peters, G.B., 1994. Theory and methodology in the study of comparative public administration. In: R. Baker, ed., Comparative public management: putting U.S. public policy and implementation in context. Westport: Praeger Publishers. pp.67-91.

Pettigrew, A. (1973) The politics of organizational decision making. London: Tavistock.

Pollit, C. and Bouckaert, G., 2011. Public management reform: a comparative analysis (3rd ed.). New York: Oxford University Press.

Ragin, C.C., 1987. The comparative method: moving beyond qualitative and quantitative strategies. Berkeley: California University Press.

Ragin, C.C., 2000. Fuzzy-set social science. Chicago: The University of Chicago Press.

Ragin, C.C., 2009. Qualitative comparative analysis using fuzzy sets (fsQCA). In: B. Rihoux and C.C. Ragin, eds. Configurational comparative methods: qualitative comparative analysis (QCA) and related techniques. California: Sage Publications, Inc. , pp.87-122.

Rihoux, B. and De Meur, G., 2009. Crisp-set qualitative comparative analysis. In B. Rihoux and C.C. Ragin, eds. Configurational comparative methods: qualitative comparative analysis (QCA) and related techniques. California: Sage Publications, Inc. pp.33-68.

Russo, I. and Confente, I., 2019. From dataset to qualitative comparative analysis (QCA)-challenges and tricky points: A research note on contrarian case analysis and data calibration. Australasian Marketing Journal, 27(2), pp.129-135.

Russo, I., Confente, I., Gligor, D. and Cobelli, N., 2019. A roadmap for applying qualitative comparative analysis in supply chain research: The reverse supply chain case. International Journal of Physical Distribution \& Logistics Management, 49(1), pp. 99-120 
Scheuch, E.K., 1990. The development of comparative research: towards causal explanation. In: E. Oyen, ed. Comparative methodology: theory and practice in international social research. London: Sage Publications, Inc. , pp.19-37.

Schutt, R.K., 2012. Investigating the Social World :The Process and Practice of Research. 7th ed. California: Sage Publications, Inc.

Skelcher, C., Klijn, E.H., Kubler, D., Sorensen, E. and Sullivan, H., 2011. Explaining the democratic anchorage of governance networks: evidence from four European countries. Administrative Theory \& Praxis, 33(1), pp.7-38.

Smelser, N.J., 1973. The methodology of comparative analysis. In: D.P. Warwick and S. Osherson, eds. Comparative research methods. New Jersey: Prentice Hall. , pp.43-86.

Thomann, E. and Maggetti, M., 2020. Designing research with qualitative comparative analysis (QCA): approaches, challenges, and tools. Sociological Methods and Research, 49(2), pp.356-386.

Thomas, D.C., 2008. Cross-Cultural Management. 2nd ed. California: Sage Publications, Inc.

Toshkov, D., 2016. Research Design in Political Science. New York: Palgrave.

Tuene, H., 1990. Comparing countries: lessons learned. In: E. Oyen, ed. Comparative methodology: theory and practice in international social research. London: Sage Publications, Inc., pp.38-62.

Wada, S., Kajüter, P. and Moeschler, M., 2012. Comparative studies of cost accounting practices in Japan and Germany. Asia-Pacific Management Accounting Journal, 7(1), pp.95-114.

Warwick, D.P. and Osherson, S., 1973. Comparative research methods: an overview. In: D.P. Warwick and S. Osherson, eds. Comparative research methods. New Jersey: Prentice Hall. , pp.3-41.

Whetten, D.A., 2009. Organizational comparative analysis: investigating similarities and differences among organizations. Research in Sociology of Organisations, 26, pp.63-87.

Wiesel, F. and Modell, S., 2014. From new public management to new public governance? hybridization and implications for public sector consumerism. Financial Accountability \& Management, 30(2), pp.175-205.

Williamson, O.E., 1981. The economics of organization: the transaction cost approach. American Journal of Sociology, 87(3), pp.548-577.

Wilson, D., 2011. Comparative analysis in public management: reflections on the experience of a major research programme. Public Management Review, 13(2), pp.293-308.

Woodside, A.G., 2016. The good practices manifesto: overcoming bad practices pervasive in current research in business. Journal of Business Research, 69(2), pp.365-381.

Yamasaki, S. and Rihoux, B., 2009. A commented review of applications. In: B. Rihoux and C.C. Ragin, eds. Configurational comparative methods: qualitative comparative analysis (QCA) and related techniques. California: Sage Publications, Inc. , pp.123-146.

Yin, R.K., 2014. Case study research: design and methods. California: Sage Publications Inc.

Ying, S.X. and Patel, C., 2016. Skeptical Judgments and self-construal: a comparative study between Chinese accounting students in Australia and China. Journal of International Accounting Research, 15(3), pp.97-111. 